\title{
SARS-CoV-2: ACE inhibitors, disastrous or desirable?
}

\author{
Leclézio $\mathrm{A}^{1}$, Robinson $\mathrm{J}^{2}$, Banerjee $\mathrm{I}^{3 *}$
}

\section{*Corresponding author:}

Dr. Indrajit Banerjee

Associate Professor, Department of Pharmacology, Sir Seewoosagur Ramgoolam Medical College, Mauritius

Email: indrajit18@gmail.com ORCID

\section{Information about the article:}

Received: June 07, 2020

Accepted: June 29, 2020

Published online: June 30, 2020

\section{Cite this article:}

Leclézio A, Robinson J, Banerjee I. SARS-CoV-2:

ACE inhibitors, disastrous or desirable? Journal of

Biomedical Sciences. 2020;7(1):40-46

\section{Publisher}

Nepal Health Research Society, Bahundhara -6, Gokarnesowor Municipality, Kathmandu, Nepal

eISSN 2382-5545, ISSN 2676-1343 (Print)

(c) The Author(s). 2020

Content licensing: CC BY 4.0

\section{ABSTRACT \\ Background}

The world has a current total of $6,663,304$ confirmed cases of COVID-19 with a death count of 392,802 deaths according to the WHO (6 June 2020). Various risk factors for the acquisition and subsequent development of deadly complications due to the virus have been established. One such risk factor is the presence of cardiovascular disease, particularly hypertension as a comorbidity. It must be noted that JNC 8 advise the use of angiotensin-converting enzyme inhibitors or angiotensin receptor blockers as first line drugs for the management of hypertension. ARDS is caused by the activation of angiotensin I, angiotensin II and AT1 receptor pathway, however stimulation of Mas receptor, MRGPR receptors, AT2 receptor and the ACE-2angiotensin (1-7), pathways is found to be defensive. Mas receptor exerts an inhibitory effect on inflammation and cellular growth and vascular mechanisms. This research aims to examine the relationship between ACE inhibitors and the risk of COVID-19 infections with the goal of determining whether this relationship is spurious in association or whether it is causative in nature? More specifically, in this research article we will determine whether the SARS-CoV-2 virus has an affinity for ACE 2 receptors in humans. Furthermore, it will be determined whether ACE inhibitors would inhibit or facilitate an imminent COVID-19 infection in individuals as well as to determine whether patients currently using ACE inhibitors should continue or discontinue the drug therapy in order to minimize their susceptibility to acquiring COVID-19, and whether patients should start ACE inhibitor therapy if required during this pandemic.

\section{Conclusion}

It is evident that ACE 2 receptors are the portal of entry for SARS-CoV-2. It is recommended that the use of RAAS inhibitors, viz ACE inhibitors and angiotensin receptor blockers is not stopped or decreased despite the ongoing pandemic as the results thereof may lead to the worsening of the patient's comorbidity and may hasten death.

\section{Keywords}

ACE 2 receptors, ACE inhibitors, angiotensin-converting enzyme inhibitors, COVID-19, SARS-CoV-2 


\section{Background}

Severe acute respiratory syndrome coronavirus 2 (SARSCoV-2) is a single-stranded RNA virus which surfaced in Wuhan, China, in 2019 [1]. In the wake of this virus, the world has been thrown into turmoil [2]. The 1st of December 2019 marked the first COVID-19 case [3]. The viral transmission was not curtailed and spread from mainland China; [4] with the first foreign case being confirmed in Thailand on the 13th of January 2020 [5]. The world has a current total of 6,663,304 confirmed cases of COVID-19 with a death count of 392,802 deaths according to the WHO (4:43pm CEST, 6 June 2020) [5]. Various risk factors for the acquisition and subsequent development of deadly complications due to the virus have been established. One such risk factor is the presence of cardiovascular disease, particularly hypertension [6] as a comorbidity [7]. A Global brief on hypertension by the WHO, indicates that there are more than 1 billion patients suffering from hypertension worldwide [8]. It must be noted that JNC 8 advises the use of angiotensinconverting enzyme inhibitors or angiotensin receptor blockers (ARB) as first line drugs for the management of hypertension [9]. The common Angiotensin Converting Enzyme Inhibitors (ACE I) which are available and used clinically are Enalapril, Lisinopril, Ramipril, Fosinopril, Quinapril, Trandolapril, Perindopril.

Angiotensin receptor blockers (ARB) which are available and used clinically are Losartan, Candesartan, Olmesartan, Telmisartan, Valsartan, Irbesartan and Irbesartan. Angiotensin Converting Enzyme Inhibitors (ACEI) have been a mainstay treatment for diseases such as post myocardial infarction, hypertension, scleroderma crisis, left ventricular dysfunction and diabetic nephropathy [10].

\section{Mechanism of action and pharmacological actions}

ACEI acts via the inhibition of angiotensin- converting enzyme, this enzyme thereby is not functional and does not convert angiotensin I to angiotensin II [11]. Angiotensin II produces vasoconstriction, increases thirst, induces aldosterone secretion, renal sodium retention, $\mathrm{ADH}$ release, increases the cardiac contractility and increases blood pressure. The resultant effect of the inhibition of the conversion of Angiotensin I to Angiotensin II is a lower blood pressure, prevention of smooth muscle and cardiac myocyte remodeling. The ACEI thereby causes a decreased arteriovenous pressure in combination with reducing the preload and afterload of the heart [12]. The use of ACEI on prolonged therapy causes a phenomenon termed as "upregulation". The usage of the angiotensin- converting enzyme inhibitor results in decreased binding of angiotensin II to the target receptor. It is noted that the organs which contain these ACE 2 receptors are the kidney, stomach, urinary bladder, lung alveolar epithelium, ileum, nasal mucosa and the heart. These organs express a large number of these ACE
2 receptors in response to the decreased level of Angiotensin II in reciprocation to the use of ACEI [12].

\section{ACE 2 receptors in COVID-19}

According to a study conducted by Kannan et al., concluded that SARS-CoV-2 virus targets these very ACE 2 receptors in humans, causing the severe pathological symptoms which may result in death [13]. Is the phenomenon of "upregulation" of these ACE 2 receptors, increasing the targets for the virus and thus is it facilitating the entry as well as accelerating the disease process of COVID-19? Hypertension is an established risk factor for the acquisition of the virus; is this precedent being further precipitated by the use of ACEI? It is therefore imperative to determine whether this relationship is spurious in association or whether it is causative in nature or whether ACEI's have any effect on the viral acquisition and disease progress at all. ARDS is caused by the activation of angiotensin I, angiotensin II and AT1 receptor pathway, however stimulation of Mas receptor, MRGPR receptors, AT2 receptor and the ACE2-angiotensin (1-7), pathways is found to be defensive as the $[14,15]$ Mas receptor exerts an inhibitory effect on inflammation cellular growth and vascular mechanisms $[16,17]$.

\section{Potential harm in the use of ACE inhibitors in COVID-19}

It has been established that the viral receptor of SARS$\mathrm{CoV}-2$ is the ACE-2 receptor. Due to this fact, there are speculations that there is a greater hazard associated to medicines that act on the renin angiotensin aldosterone system (RAAS) in patients with COVID-19 [19]. According to the hypothesis formulated by Watkins J. ACE inhibitors could be a risk factor for COVID-19 and recommended for swift epidemiological and preclinical studies take place, as well as called for the temporarily replacement of ACEI by other drugs by virtue that the SARS-CoV-2 infection increased ACE2 expression and could be more harmful for the patients [20, 21]. According to Diaz JH hypothesis, patients who received Angiotensin converting enzyme inhibitors and Angiotensin receptor blockers may be in jeopardy of severe disease consequences due to SARSCoV-2 infections [22]. Verdecchia $\mathrm{P}$ and his team from Italy used this concept, to produce the hypothesis that the use of Angiotensin converting enzyme inhibitors would cause an upsurge in appearance of ACE 2 receptors and would thus allow an increased number of ports of entry for the access of the SARS-CoV 2 virus. If proven to be true, the use of ACE inhibitors would be further increasing the risk in a cohort of the population who have concomitant comorbidities, thus making them extremely vulnerable to the infection [23]. In a study conducted by Fang L has reported diabetes, hypertension, coronary artery disease and cerebrovascular disease as the most common comorbid 


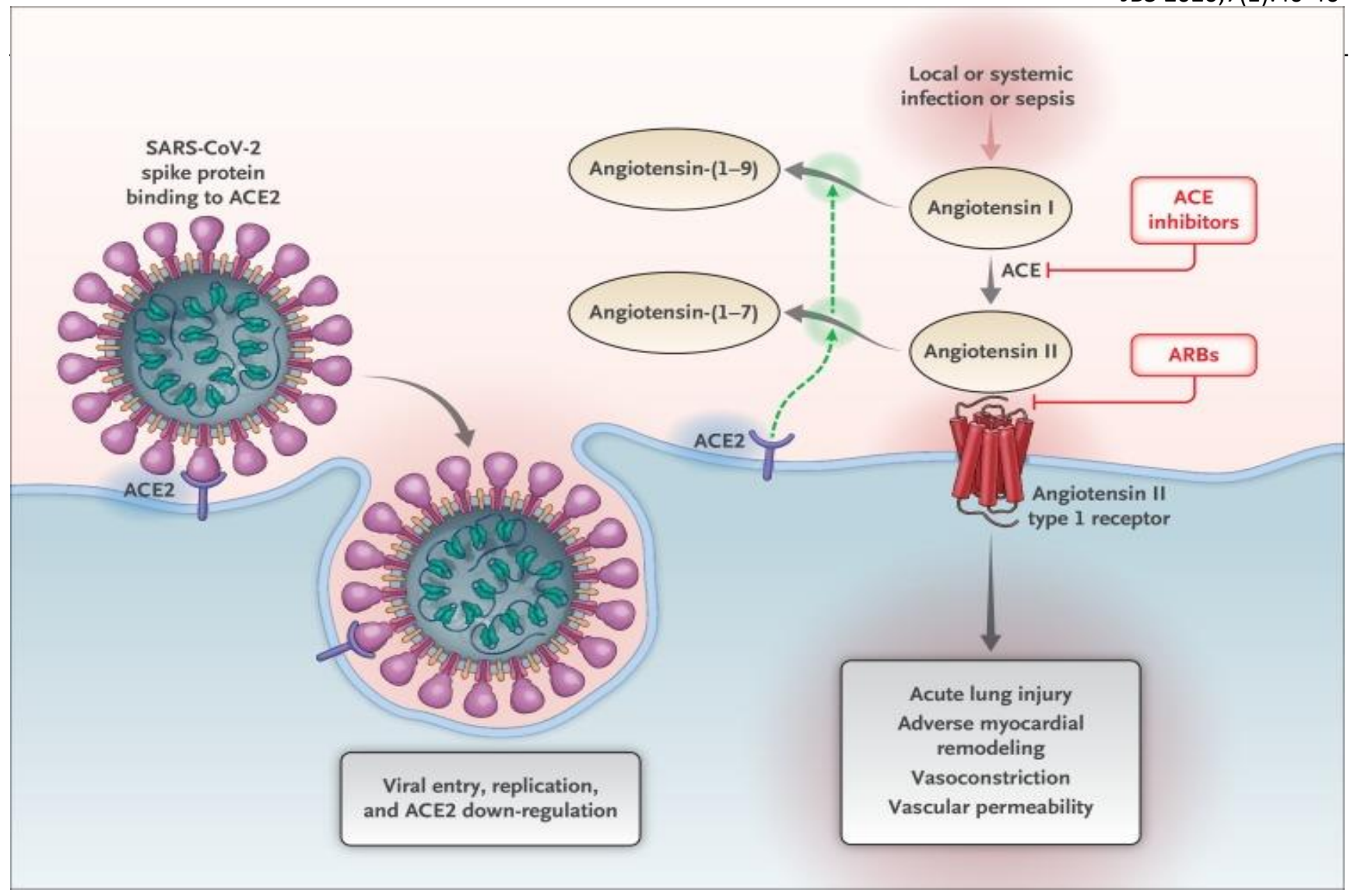

Figure 1: SARS-CoV-2 and the renin angiotensin aldosterone system

Source: Vaduganathan et al. Renin-AngiotensinAldosterone System Inhibitors in Patients with Covid-19. N Engl J Med. 2020;382(17):1653-1659 [18].

condition in COVID-19 patients based on three studies from China. Most of the patients were treated by angiotensin-converting enzyme inhibitors; however, treatment was not evaluated in either study [24]. More severe COVID-19 disease outcomes (such as intensive care and mechanical ventilation) were reported in patients with cardio-vascular diseases, such as hypertension, coronary artery disease and diabetic nephropathy [25]. It was evident that all these patients met the recommendations for and were most likely treated by ACEIs and ARBs. ACEIs / ARBs and COVID-19 were believed to have a potential association in this study, and this raised the question of whether patients on ACEI and ARBs should change their therapeutic regimen. The study did however state that future case-control studies were needed to confirm the use of these drugs as being a risk factor for facilitating the pathogenicity of SARS-CoV-2 $[24,25]$. A study conducted by Liang Cheng et al., concluded that cardiac injury was a prevalent and often fatal complication that precipitated in patients with COVID-19. The study discovered that the pericytes of the heart expressed these ACE 2 receptors in high concentration. The virus thereby using these receptors as portals to cause vascular dysfunction which could precipitate in a myocardial infarction and further complications. The expression of ACE 2 receptors in heart failure patients and on RAAS inhibitors therapy will be higher in comparison to that of a normal human. This increased expression in combination with the comorbidity could potentiate the likelihood of further complications and death [26].

At this current point in time, there is not enough research and evidence to prove that RAAS inhibitors are harmful to patients who suffer from COVID-19, nor is there enough evidence to prove that the use of these drugs aids and abets the virus in its virulence or infectivity to a human undergoing this therapy.

\section{Potential advantage for the use ACE Inhibitors in COVID-19}

i. Risks of ACE I Compared to Other Antihypertensive Drugs in Covid-19

A study conducted by Reynolds et al., in New York University, compared hypertensive patients on ACE inhibitors vs other 5 common anti-hypertensives drug classes. Out of 12,594 patients who were confirmed COVID-19 positive cases (34.6\%) had a history of hypertension, among which $(59.1 \%)$ tested positive, $(24.6 \%)$ being patients with severe COVID related illness [19]. They examined the patients' clinical and drug treatment profiles and found no association between positive COVID-19 tests and any of the various 
antihypertensive medication classes, including ACEI. It was thus concluded that no drug class, not even ACEIs or ARBs were associated with a substantial increase in pathogenicity of SARS-CoV-2 [19].

In a study conducted by Mancia et al. in Italy, 6272 positive cases of COVID-19, as well as the patients' clinical profiles and information on their use of selected drugs was gathered. Compared to the control group, the case patients had higher rates of antihypertensive drugs, including ACEI and ARBs, but no causal association between ARBs or ACEI and COVID-19 was evident. Usage of Angiotensin receptor blockers and Angiotensin converting enzyme inhibitors was not found to be linked with COVID-19. The study concluded by identifying that case patients did make use of ACEI and ARBs more frequently than the control group but this was purely due to greater prevalence of cardiovascular disease. No evidence was suggestive to prove that these drugs affected the clinical course or risk of COVID-19 [27].

ii. ACE I may be protective against the respiratory complications of SARS-CoV-2

a. The respiratory complications of SARS-CoV2 due to ACE 2 downregulation:

The SARS-CoV-2 virus, after gaining entry through ACE 2 receptors, downregulates ACE 2 expression to a point where the enzyme cannot exert its protective effect on the lungs, and other organs [18, 28].

An experimental study done by Imai et al, 2005 to demonstrate how a decrease in ACE 2 receptors causes acute lung injury in animal models which mimic those seen in SARS-CoV-2 and Acute Respiratory Distress Syndrome. Namely: acid aspiration, sepsis, and pneumonia [29]. This was done via the examination of effects of ACE 2 gene deficiency in genetically modified mouse animal models with a control group of wild-type mice. When acid aspiration was induced, the ACE 2 deficient mice showed edema, bleeding, inflammatory cell infiltration, increase in the alveolar wall thickness and increased lung elastance as well as lower oxygenation [29]. This is a perfect demonstration of how decreased ACE 2 (and its subsequent increase in ACE1 activity) caused by corona virus leads to acute lung injury.

\section{b. Evidence that increasing ACE 2 levels helps reverse acute lung injury:}

As a solution to the problem of acute lung injury caused by decreased ACE 2, would be to increase the level of ACE 2 in the lungs [29]. One way to do this would be via administering recombinant human angiotensin converting enzyme 2 (rhuACE 2).

In a study by Imai et al, 2005 performed a rescue experiment using the administration of rhuACE to those mice with acute lung injury, and they found that the lung injury process was reversed. The lung elastance and pulmonary edema decreased drastically in the Ace 2 deficient mice and it decreased the control group mice as well. This shows that ACE 2 activity can be directly protective from acute lung injury [29].

In a 2017 pilot trial by Khan et al. in 10 intensive care units in the United States, increasing the ACE 2 activity through the administration of Recombinant Human Angiotensin-converting Enzyme 2 (rhACE-2) was also proven to reverse the lung injury process [30]. The ARDS Patients were administered rhACE-2 and this increased the levels of Angiotensin (1-7) which has antiinflammatory properties and alveolar surfactant protein D levels, which is inclined to decrease interleukin-6 which has pro-inflammatory properties which may cause acute lung injury [30].

c. ACE1 inhibitors can be used to increase ACE 2 levels and thus reverse acute lung injury

A study was conducted by Huang et al. to determine if ACE inhibitors could upregulate ACE-2 expression. This was done on rats to determine whether the admission of ACE inhibitors would upregulate the ACE 2 receptors in those rats after inducing liver injury. There was marked upregulations of expression of ACE 2 in tetrachlorideinjured rate liver and Angiotensin II preserved hepatic stellate cells after ACEIs were administered. This confirmed his hypothesis that Angiotensin converting enzyme inhibitors are able to upregulate ACE 2 expression [31].

ACE-2 in cardiac myocytes was found to be amplified when ACE inhibitors where administered over 1-2 weeks. [32]. Thus, ACE inhibitors could be used to increase ACE levels and thus reverse acute lung injury. However, this is a hypothesis, and still needs to be proven with clinical trials.

A study conducted by Sun et al, suggested that elevated levels of ACE and Angiotensin II paint a dire prognostic picture for the progression of pneumonia. Research conducted on animals shows that ACEI's and ARB's (RAAS blockers) alleviate the severe symptoms associated with respiratory infections and even respiratory failure. The use of ACEI may prove beneficial in the drug therapy for patients with COVID-19 according to these results based on pneumonia [33].

\section{iii. Discontinuing Existing ACEI and ARB therapy may prove harmful for COVID-19}

Since ACEI blunt the deleterious effects of Angiotensin II, enhance the ACE-2 and reduce harmful effects on the lungs of COVID-19[30], discontinuing the ACEI may not only deprive the patients of their beneficial properties but it could also increase the severity of their cardiovascular comorbidity making their body less equipped to deal with the SARS-CoV-2 infection, ultimately precipitating in severe conditions or death [30].

Evidence from a Systematic Review and Meta-analysis by Zhang X on 19,000 COVID-19 patients on ACEI or ARB, 


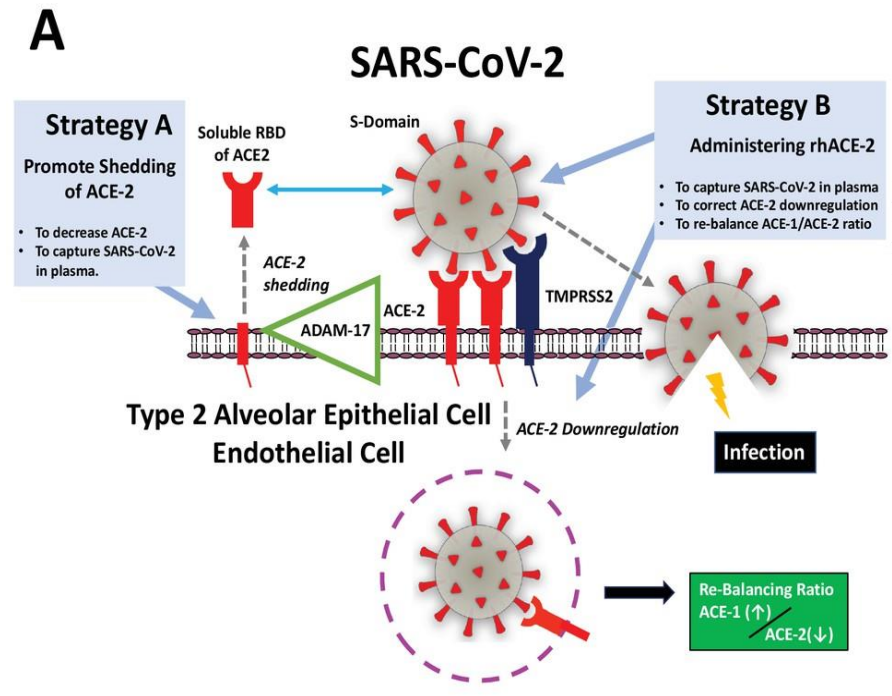

B

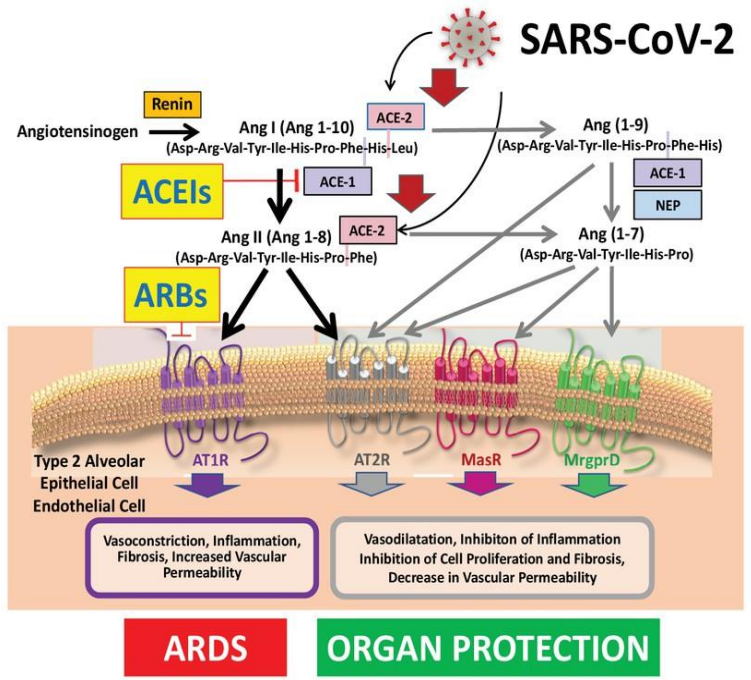

Figure 2: SARS-Cov-2 and lower airway

Source: Rossi et al. Potential harmful effects of discontinuing ACE-inhibitors and ARBs in COVID-19 patients. Elife. 2020;9:e57278 [15]

showed that there was no evidence suggestive of increase incidence of COVID-19 infection in the patients. Furthermore, it was reported that Angiotensin Converting Enzyme Inhibitors and Angiotensin receptor blockers were allied to a lower hazard of mortality compared to other antihypertensive drugs [34].

\section{iv. Refuting the "Harmful Effects" of ACEI in COVID-} 19

The 2020 descriptive analysis of 1099 patients in China uses the fact that many COVID-19 infections occur in hypertensives that meet the requirement for ACEI as an indicator that ACEI may be worsening the clinical course of
COVID-19 infections. This could be a spurious association. As the various complications associated with hypertension itself may be the reason why the patients are not able to cope with the disease. Secondly, not all hypertensive patients are taking ACE inhibitors as drugs - according to a population-based study in China, only 30 to $40 \%$ of hypertensives are treated with any antihypertensives, and of those only $25-30 \%$ of patients are put on RAAS inhibitors [18]. Many hypertensive patients are older, and advancing age is the strongest predictor of COVID-19 related death. [13] It therefore likely that there is no substantial evidence supporting the claim that ACEI worsen the clinical course of COVID-19 [35].

\section{Conclusion}

It is evident that ACE 2 receptors are the portal of entry for SARS-CoV-2. Various clinical trials across the globe are underway to further assess the safety margin and the likelihood of the use of Angiotensin Converting Enzyme Inhibitors, Angiotensin receptor blockers and recombinant human ACE2 in the treatment of the COVID-19 disease. It is recommended that the use of renin angiotensin aldosterone system inhibitors, viz ACE inhibitors and angiotensin receptor blockers is not stopped or decreased despite the ongoing pandemic as the results thereof may lead to the worsening of the patient's comorbidity and may hasten death.

\section{Abbreviations}

Angiotensin converting enzyme inhibitors (ACE I), Angiotensin receptor blockers (ARB), anti diuretic hormone $(\mathrm{ADH})$, acute respiratory distress syndrome (ARDS), joint national committee on detection, evaluation, and treatment of high blood pressure guidelines 8 (JNC 8), Severe acute respiratory syndrome coronavirus 2 (SARS-CoV-2), Coronavirus disease (COVID-19), renin angiotensin aldosterone system (RAAS), Recombinant human angiotensin converting enzyme 2 (rhuACE 2), World Health Organization (WHO)

\section{Acknowledgments}

We extend our intense gratitude to the Chairman Mr. RPN Singh and Prof. Namrata Chhabra, Principal In charge Sir Seewoosagur Ramgoolam Medical College, Mauritius for providing us with huge support and guidance to conduct the research study effectively.

\section{Authors' contribution}

a. Study planning: IB

b. Manuscript writing: AL, JR

c. Manuscript revision: AL, JR, IB

d. Final approval: AL, JR, IB

e. Agreement to be accountable for all aspects of the work: $\mathrm{AL}, \mathrm{JR}, \mathrm{IB}$ 


\section{Funding}

There was no funding for this work.

\section{Availability of data and materials}

All data and materials available as part of the article, and no additional source data are required.

\section{Competing interests}

There is no conflict of interest for any author of this manuscript.

\section{Publisher's Note}

NHRS remains neutral with regard to jurisdictional claims in published maps and institutional affiliations.

The publisher shall not be legally responsible for any types of loss, actions, claims, proceedings, demand or costs or damages whatsoever or howsoever caused arising directly or indirectly in connection with or arising out of the use of this material.

\section{Author information}

${ }^{1}$ Alexandra Leclézio, Final Part II medical student, Sir Seewoosagur Ramgoolam Medical College, Mauritius ORCID

${ }^{2} \mathrm{Mr}$. Jared Robinson, 2nd Professional medical student, Sir Seewoosagur Ramgoolam Medical College, Mauritius ORCID

${ }^{3}$ Dr Indrajit Banerjee, Associate Professor, Department of Pharmacology, Sir Seewoosagur Ramgoolam Medical College, Mauritius ORCID

\section{References}

1. Guo YR, Cao QD, Hong ZS, Tan YY, Chen SD, Jin $\mathrm{HJ}$, et al. The origin, transmission and clinical therapies on coronavirus disease 2019 (COVID-19) outbreak - an update on the status. Mil Med Res. 2020;7(1):11.

https://doi.org/10.1186/s40779-020-00240-0

2. Hui R. Hypertension Drug Therapy. Adv Exp Med Biol. 2020;1177:149-268. doi:10.1007/978-981-152517-9_6 https://doi.org/10.1007/978-981-15-2517-9_6

3. Anastassopoulou C, Russo L, Tsakris A, Siettos C. Data-based analysis, modelling and forecasting of the COVID-19 outbreak. PLoS One. 2020;15(3):e0230405. https://doi.org/10.1371/journal.pone.0230405

4. Chen N, Zhou M, Dong X, Qu J, Gong F, Han Y, et al. Epidemiological and clinical characteristics of 99 cases of 2019 novel coronavirus pneumonia in Wuhan, China: a descriptive study. Lancet. 2020;395(10223):507-13. https://doi.org/10.1016/S0140-6736(20)30211-7

5. WHO Coronavirus Disease (COVID-19)
Dashboard. https://COVID-19.who.int/ (Accessed on 07 June, 2020)

6. Guo T, Fan Y, Chen M, Wu X, Zhang L, He T, et al. Cardiovascular Implications of Fatal Outcomes of Patients With Coronavirus Disease 2019 (COVID19. JAMA Cardiol. 2020; 201017. https://doi.org/10.1001/jamacardio.2020.1017

7. Gupta R, Misra A. Contentious issues and evolving concepts in the clinical presentation and management of patients with COVID-19 infection with reference to use of therapeutic and other drugs used in Co-morbid diseases (Hypertension, diabetes etc). Diabetes Metab Syndr. 2020;14(3):251-4. https://doi.org/10.1016/j.dsx.2020.03.012

8. Hypertension: World Health Organization (WHO). Available from: https://www.who.int/healthtopics/hypertension/\#tab=tab_1 [Accessed 7/06/2020]

9. Jarari N, Rao N, Peela JR, Ellafi KA, Shakila S, Said AR, et al. A review on prescribing patterns of antihypertensive drugs. Clin Hypertens. 2016;22:7. Published 2016 Mar 27. https://doi.org/10.1186/s40885-016-0042-0

10. Herman LL, Padala SA, Annamaraju P, Bashir K. Angiotensin Converting Enzyme Inhibitors (ACEI) [Updated 2020 Apr 7]. In: StatPearls [Internet]. Treasure Island (FL): StatPearls Publishing; 2020 Jan-. Available from: https://www.ncbi.nlm.nih.gov/books/NBK431051/

11. Tabacova S. Mode of action: angiotensin-converting enzyme inhibition--developmental effects associated with exposure to ACE inhibitors. Crit Rev Toxicol. 2005;35(8-9):747-55. https://doi.org/10.1080/10408440591007160

12. Huang ML, Li X, Meng Y, Xiao B, Ma Q, Ying SS, et al. Upregulation of angiotensin-converting enzyme (ACE) 2 in hepatic fibrosis by ACE inhibitors. Clin Exp Pharmacol Physiol. 2010;37(1):e1-e6. https://doi.org/10.1111/j.1440-1681.2009.05302.x

13. Kannan S, Shaik Syed Ali P, Sheeza A, Hemalatha K. COVID-19 (Novel Coronavirus 2019) - recent trends. Eur Rev Med Pharmacol Sci. 2020;24(4):2006-11. https://doi.org/10.26355/eurrev_202002_20378

14. Yu X, Cui L, Hou F, Liu X, Wang Y, Wen Y, et al. Angiotensin-converting enzyme 2-angiotensin (1-7)Mas axis prevents pancreatic acinar cell inflammatory response via inhibition of the p38 mitogen-activated protein kinase/nuclear factor- $\kappa \mathrm{B}$ pathway. Int J Mol Med. 2018;41(1):409-20. https://doi.org/10.3892/ijmm.2017.3252

15. Rossi GP, Sanga V, Barton M. Potential harmful effects of discontinuing ACE-inhibitors and ARBs in COVID-19 patients. Elife. 2020;9:e57278. https://doi.org/10.7554/eLife.57278 
16. Simões e Silva AC, Silveira KD, Ferreira AJ, Teixeira MM. ACE2, angiotensin-(1-7) and Mas receptor axis in inflammation and fibrosis. $\mathrm{Br} \mathrm{J}$ Pharmacol. 2013;169(3):477-92. https://doi.org/10.1111/bph.12159

17. Karnik SS, Singh KD, Tirupula K, Unal $H$. Significance of angiotensin 1-7 coupling with MAS1 receptor and other GPCRs to the reninangiotensin system: IUPHAR Review 22. $\mathrm{Br}$ J Pharmacol. 2017;174(9):737-53. https://doi.org/10.1111/bph.13742

18. Vaduganathan M, Vardeny O, Michel T, McMurray JJV, Pfeffer MA, Solomon SD. Renin-AngiotensinAldosterone System Inhibitors in Patients with Covid-19. N Engl J Med. 2020;382(17):1653-9. https://doi.org/10.1056/NEJMsr2005760

19. Reynolds HR, Adhikari S, Pulgarin C, Troxel AB, Iturrate E, Johnson SB, et al. Renin-AngiotensinAldosterone System Inhibitors and Risk of Covid-19 [published online ahead of print, 2020 May 1]. N Engl J Med. 2020;NEJMoa2008975.

https://doi.org/10.1056/NEJMoa2008975

20. Watkins J. Preventing a covid-19 pandemic. BMJ. 2020;368:m810. https://doi.org/10.1136/bmj.m810

21. Esler M, Esler D. Can angiotensin receptor-blocking drugs perhaps be harmful in the COVID-19 pandemic?. J Hypertens. 2020;38(5):781-2. https://doi.org/10.1097/HJH.0000000000002450

22. Diaz JH. Hypothesis: angiotensin-converting enzyme inhibitors and angiotensin receptor blockers may increase the risk of severe COVID-19. J Travel Med. 2020;27(3):taaa041. https://doi.org/10.1093/jtm/taaa041

23. Verdecchia P, Reboldi G, Cavallini C, Mazzotta G, Angeli F. ACE-inibitori, sartani e sindrome respiratoria acuta da coronavirus 2 [ACE-inhibitors, angiotensin receptor blockers and severe acute respiratory syndrome caused by coronavirus]. G Ital Cardiol (Rome). 2020;21(5):321-7.

24. Fang L, Karakiulakis G, Roth M. Are patients with hypertension and diabetes mellitus at increased risk for COVID-19 infection? [published correction appears in Lancet Respir Med. 2020 May 18]. Lancet Respir Med. 2020;8(4):e21. https://doi.org/10.1016/S2213-2600(20)30116-8

25. Guan WJ, Ni ZY, Hu Y, Liang WH, Ou CQ, He JX, et al. Clinical Characteristics of Coronavirus Disease 2019 in China. N Engl J Med. 2020;382(18):1708-20. https://doi.org/10.1056/NEJMoa2002032

26. Chen L, Li X, Chen M, Feng Y, Xiong C. The ACE 2 expression in human heart indicates new potential mechanism of heart injury among patients infected with SARS-CoV-2. Cardiovasc Res. 2020;116(6):1097-100. https://doi.org/10.1093/cvr/cvaa078

27. Mancia G, Rea F, Ludergnani M, Apolone G, Corrao G. Renin-Angiotensin-Aldosterone System Blockers and the Risk of Covid-19 [published online ahead of print, 2020 May 1]. N Engl J Med. 2020; NEJMoa2006923. https://doi.org/10.1056/NEJMoa2006923

28. Li W, Moore MJ, Vasilieva N, Sui J, Wong SK, Berne MA, et al. Angiotensin-converting enzyme 2 is a functional receptor for the SARS coronavirus. Nature. 2003;426(6965):450-454. https://doi.org/10.1038/nature02145

29. Imai Y, Kuba K, Rao S, Huan Y, Guo F, Guan B, et al. Angiotensin-converting enzyme 2 protects from severe acute lung failure. Nature. 2005;436(7047):112-116. doi:10.1038/nature03712 https://doi.org/10.1038/nature03712

30. Khan A, Benthin C, Zeno B, Albertson TE, Boyd J Hall R, et al. A pilot clinical trial of recombinant human angiotensin-converting enzyme 2 in acute respiratory distress syndrome. Crit Care 21, 234 (2017). https://doi.org/10.1186/s13054-017-1823-X

31. Lubel JS, Herath CB, Tchongue J, Grace J, Jia Z, Spencer K, et al. Angiotensin-(1-7), an alternative metabolite of the renin-angiotensin system, is upregulated in human liver disease and has antifibrotic activity in the bile-duct-ligated rat. Clin Sci (Lond). 2009;117(11):375-386. https://doi.org/10.1042/CS20080647

32. $\mathrm{K}$ Aronson, Robin E. Ferner Drugs and the reninangiotensin system in covid-19 BMJ 2020; 369 https://doi.org/10.1136/bmj.m1313

33. Sun ML, Yang JM, Sun YP, Su GH. Zhonghua Jie $\mathrm{He} \mathrm{He} \mathrm{Hu} \mathrm{Xi}$ Za Zhi. 2020;43(0):E014. https://doi.org/10.3760/cma.j.issn.10010939.2020 .0014

34. Zhang X, Yu J, Pan LY, Jiang HY. ACEI/ARB use and risk of infection or severity or mortality of COVID-19: A systematic review and meta-analysis [published online ahead of print, 2020 May 15]. Pharmacol Res. 2020;158:104927. https://doi.org/10.1016/j.phrs.2020.104927

35. Speth RC. Keep taking your ACE inhibitors and ARBs during the COVID 19 pandemic. J Travel Med. 2020;27(3):taaa045. https://doi.org/10.1093/jtm/taaa045 